Recepción: 11 / 01 / 2017

Aceptación: 27 / 04 / 2017

Publicación: 15 / 06 / 2017

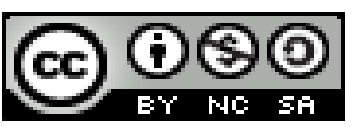

Ciencias económicas y empresariales Artículo de Investigación

\title{
El marketing como estrategia para la fidelización del cliente
}

\author{
Marketing as a strategy for customer loyalty \\ Marketing como uma estratégia para a fidelidade do cliente \\ Raúl F. Villalba-Miranda ${ }^{\mathrm{I}}$ \\ raulvillalba59@yahoo.es \\ Ricardo P. Medina-Chicaiza " \\ medina_patricio@yahoo.es \\ Jorge F. Abril-Flores ${ }^{\text {II }}$ \\ jabrilflores@yahoo.es
}

Correspondencia: raulvillalba59@yahoo.es

Magister en Gestión Estratégica Empresarial Mba., Ingeniero Comercial, Licenciado en Ciencias Administrativas, Docente de la Universidad Técnica de Ambato, Ambato, Ecuador.

" Magister en Tecnología de la Información y Multimedia Educativa, Diploma Superior en Gerencia Informática, Diploma Superior en Liderazgo Institucional, Docente de Universidad Técnica de Ambato/Universidad Católica Sede Ambato, Ambato, Ecuador.

III Magister en Docencia y Currículo para la Educación Superior, Magister en Administración de Empresas Mención Planeación, Doctor en Contabilidad y Auditoría, Licenciado en Contabilidad y Auditoría, Contador Público, Docente de UNIANDES, Ambato, Ecuador. 


\title{
Resumen
}

La lealtad o fidelidad del cliente, es incuestionablemente una cualidad. Su lealtad es un atributo o rasgo que se puede medir, y, en general, los clientes muestran altos o bajos niveles de lealtad. En el proceso de gestión de relaciones con los clientes, se impone encontrar modos para aumentar su fidelidad. Debe entenderse, para esto, que existe un específico ciclo de vida del servicio de la relación con el cliente. La aceptación y conocimiento de esto, sirve para conocer, la etapa en que se puede hacer hincapié para conseguir los objetivos de fidelización. Este artículo aborda la atención a la fidelización, tomándola como una estrategia de marketing.

Palabras clave: fidelización; estrategia de marketing; fidelización de clientes.

\begin{abstract}
Loyalty or customer loyalty is unquestionably a quality. Their loyalty is an attribute or trait that can be measured, and, in general, customers show high or low levels of loyalty. In the process of managing customer relationships, it is imperative to find ways to increase their loyalty. It must be understood, for this, that there is a specific service life cycle of the relationship with the customer. The acceptance and knowledge of this, serves to know, the stage in which can be emphasized to achieve the objectives of loyalty. This article addresses the attention to loyalty, taking it as a marketing strategy.
\end{abstract}

Keywords: loyalty; marketing strategy; customer loyalty.

\section{Resumo}

Fidelidade ou lealdade do cliente é, sem dúvida, uma qualidade. Sua lealdade é um atributo ou característica que pode ser medido e, em geral, os clientes mostram níveis elevados ou baixos de lealdade. No processo de gestão de relacionamento com o cliente, que impõe encontrar maneiras de aumentar a sua lealdade. Deve ser entendido, por isso, há um ciclo de vida do serviço específico da relação com o cliente. Aceitação e conhecimento deste, usado para saber, o estágio pode ser enfatizada para alcançar a lealdade objetivos. Este artigo discute atenção à lealdade, tomando-o como uma estratégia de marketing.

Palavras chave: lealdade; estratégia de marketing; a fidelidade do cliente 


\section{Introducción}

La fidelización, más que un objetivo de gestión, puede ser considerada como un instrumento estratégico. En la actualidad, numerosas empresas apuestan por la fidelización, como manera de confirmarse en el mercado, debido a la situación preponderante que va alcanzando el cliente en las relaciones empresa-cliente.

Se impone revisar los principales modelos de fidelización que en la actualidad se emplean como referencia. Por ejemplo, Vera (2012), se refiere a la fidelización posicionándose en el futuro, en hacerle saber al cliente cómo le contribuye a la empresa con su presencia en el futuro.

Uno de los errores más habituales de las empresas, es no tener en consideraciones valor futurible de un cliente; es decir, cuánto van a aportar sus compras en el futuro... si sigue siendo su cliente (Vera, 2012: 37).

Desde otra perspectiva, Peppers (2012), apunta hacia la lealtad del cliente, desde dos perspectivas complementarias: la actitud y comportamiento. Desde esta noción, la lealtad de actitud tiene que ver con la preferencia del cliente; mientras que, la lealtad del comportamiento, se vincula directamente con los comportamientos cotidianos, sistemáticos y reales, al margen de la preferencia de los clientes, o sea, más allá de tal comportamiento.

En este sentido, el Instituto de Fidelización al Cliente, establece que la lealtad del cliente es "todo acerca de atraer al cliente correcto, lo que les permitió comprar, comprar menudo, comprar en mayores cantidades y traer aún más clientes."

(Novo, 2013), define la lealtad del cliente en términos de comportamiento. En concreto, afirma que la lealtad del cliente, "describe la tendencia de un cliente para elegir una empresa o producto sobre otro para una necesidad particular."

Más allá de la filosofía, (Lantares, 2014) establece que la lealtad del cliente es "el resultado de la experiencia emocional consistentemente positiva, satisfacción física basada en atributos y el valor percibido de una experiencia, que incluye los productos o servicios." A partir de esta definición, se clarifica el hecho emocional se toma en cuanta, hacia el logro de la satisfacción del cliente y/o consumidor. 
Por otro lado, Kolsky (2015), plantea dos modelos de lealtad: emocional e intelectual. En cuya postulación, Kolsky señala que la lealtad emocional responde a la interrogante de cómo el cliente se siente acerca de hacer negocios con la empresa y sus productos, y si es que "ama" lo que hace y ni cabe la posibilidad de pensar en hacer negocios con nadie más lealtad intelectual, por el contrario, se basa más transaccionalmente donde los clientes deben justificar hacer negocios con usted en lugar de otra persona.

En este sentido, varios autores coinciden en seis ejes de acción:

- Segmentación Es el segmento de clientes en el cual se deberá establecer el foco de acción de la estrategia de fidelización.

- Mapa de Cliente Se presenta como un nivel de micro-segmentación de los clientes hacia los cuales se desea llegar con la estrategia trazando una ruta hacia la cual se debe implementarla.

- Personalización Se define como el establecimiento de los aspectos personales que diferencian la estrategia hacia el cliente

- Satisfacción Se encamina hacia el impacto que tendrá en cuanto al nivel de satisfacción que se pretende conseguir una vez que se ejecute dicha estrategia.

- Incentivos Responde a la interrogante de cómo crear un sistema de incentivos para lograr un lazo de estrechez con el cliente.

- Retroalimentación Como fuente de información hacia el mejoramiento continuo y monitoreo del lanzamiento y ejecución de la estrategia, este eje permite conocer los focos de atención hacia los cuales se deben dirigir los cambios.

En tal sentido, la lealtad o fidelidad del cliente, es incuestionablemente una cualidad. Su lealtad es un atributo o rasgo que se puede medir, y, en general, los clientes muestran altos o bajos niveles de lealtad. En el proceso de gestión de relaciones con los clientes, se impone encontrar modos para aumentar su fidelidad.

Para ello, lo que se conoce como servicio de satisfacción al cliente, cumple una función primordial, ende las empresas, debido a los niveles de competitividad con que se opera en la actualidad. Varios autores coinciden en que, se puede visualizar como un conjunto de acciones 
interrelacionadas, desarrolladas por la empresa, y orientadas a la satisfacción de las necesidades actuales o futuras de los clientes. Igualmente, se reconocen aspectos de interés, en aras de conseguir la satisfacción del cliente:

- Conocer con amplitud las necesidades del cliente.

- Crear un ambiente de flexibilidad y mejoramiento continuo para adaptarse a los cambios.

- Adecuar el servicio en base al tipo de cliente.

- Plantear esquemas de fidelización como parte de sus objetivos operacionales.

- Formular constantemente estrategias para alcanzar nuevos objetivos

- Plantear un modelo de atención al cliente, como un servicio diferenciado respecto a lo que ofrece la competencia.

Se conoce que, cuando el servicio de atención al cliente supera las expectativas, se genera sensación de satisfacción y buena voluntad hacia una organización. Esto propicia una imagen positiva, y anima al cliente a volver: es decir, estamos en presencia de la lealtad del cliente.

También la satisfacción del cliente, constituye un argumento para su retención y fidelización. Numerosas empresas evalúan la satisfacción basándose en el punto de venta; sin embargo, la satisfacción y la lealtad son a menudo fuertemente descuidados y potencialmente dañados. Cualquier empresa que realmente considere el valor de la relación con el cliente, asume su experiencia total como una cartera de puntos de contacto. Con la evaluación de la satisfacción, aumentan las oportunidades para fortalecer las relaciones con clientes, que significan rentabilidad a largo plazo.

Debe entenderse, para esto, que existe un específico ciclo de vida del servicio de la relación con el cliente. La aceptación y conocimiento de esto, sirve para conocer, la etapa en que se puede hacer hincapié para conseguir los objetivos de fidelización.

En este sentido, las nuevas tecnologías tienen un impacto cada vez más profundo e irreversible en la vida cotidiana y, por supuesto, en la de los usuarios de las empresas. Para autores como Carvajal, Ormeño y Valverde (2013), es un hecho innegable, que hoy en día las nuevas tecnologías de la información y las comunicaciones, están impactando de forma significativa en las vías para informar al cliente, a través de la apertura de canales de comunicación como: 
Facebook, Youtube e Instagram; además del uso de herramientas de mensajería instantánea para enviar a los clientes promociones, noticias y comunicaciones en general.

De ahí que se pueda ahondar en el llamado marketing tecnológico, que, para estos mismos autores, es el empleo de Tecnologías de la Información y las Comunicaciones en aras de desarrollar y hacer más eficientes las labores del mercadeo. Por otra parte, sirven para brindar una mejor y más esmerada atención al cliente, ofreciendo una nueva gama de posibilidades para que las empresas emulen su presencia online, reforzando la imagen corporativa y sumando valor al servicio, con respecto a la competencia.

En este sentido, merece una especial atención, lo que se conoce como marketing viral. En palabras de Bello (2011) será el tipo de marketing que se consigue mediante la incorporación empresarial de las Tecnologías de la Información, sirviéndose de la publicidad en forma de boca a oreja. Se puede compartir con un clic, y se replica en forma vertiginosa (viral), mediante las redes sociales.

Este es posible mediante el reenvío de correos electrónicos, y el manejo de la opción Compartir: una herramienta básica de las redes sociales. Con ello se repercute en el mercado con facilidad y se ahorran costos por concepto de contrato de campañas comunicativas para promocionar eventos, promociones, ofertas y publicidad en general. Autores como Río, Domínguez y Garrido (2014) apuntan que, el marketing viral sirve como táctica, de empresas y organizaciones, para ejercitar y fortalecer canales de comunicación.

En este sentido, autores de diversos espacios, en forma interesante, se han referido a los factores que influyen en la lealtad de los clientes, desde los enfoques: internos y externos, a fin de establecer una metodología mejorada de fidelización a través del establecimiento de un modelo de lealtad, y acerca de la evolución en la investigación de la lealtad del cliente, con respecto a las tendencias de marketing, desde los puntos de vista: transaccional y relacional. Asimismo, el estudio titulado Análisis de los procesos del área Comercial e implementación de un programa de mejoramiento Continuo para la empresa camposantos del Ecuador S.A. en la ciudad de Guayaquil, de Noboa \& Castro (2015), plantea de forma interesante un plan ampliamente estructurado para el mejoramiento continuo, en el cual se aborda la fidelización como una problemática y como uno de los principales focos de acción, para el cual realizan primero un 
estudio a nivel comercial de la empresa objeto de estudio para indagar en sus procesos y conocer como estos pueden ser mejorados en la adaptación de las mejores estrategias de mejoramiento continuo.

Las autoras miden a la fidelidad de los clientes de la empresa como un indicador clave del negocio para conocer la probabilidad de que los clientes frecuenten y compren el producto y servicio ofrecido por la empresa, justamente para lograr un incremento de ventas en forma sostenible. Se hace mención a la capacitación de los empleados de la empresa como un proceso que forma parte del plan de fidelización, puesto que el talento humano es un factor preponderante para lograr sostener el modelo trazado. Otro de los aspectos tratados en este trabajo, hace referencia al aprendizaje necesario para escuchar y comprender la voz del cliente, como una fuente de retroalimentación primaria, a fin de lograr un mejoramiento continuo basada en las necesidades planteadas por los propios clientes. Otro enfoque de especial consideración en este trabajo se relaciona con la satisfacción del cliente visto como un factor para lograr un incremento en la rentabilidad de la empresa, puesto que ambas cosas se interrelacionan en forma directa.

Desde otra perspectiva, el modelo de Kotler referenciado por (Alcaide, 2015), plantea un modelo de especial trascendencia, para alcanzar una fidelización de clientes exitosa. Este modelo fue presentando como una premisa de trabajo hacia el logro efectivo de la fidelización de clientes, en el Marco Mundial Marketing y Ventas, efectuado en Barcelona.

Algunas de sus principales premisas:

1. Examinar el creciente poder de negociación del cliente- Generalmente el cambio y actualización de las políticas de la fidelización, se producen a causa del creciente poder tanto del cliente, así como también del consumidor que estos van adquiriendo con el transcurrir de los días. Un ejemplo muy claro de este tipo de casos es el uso creciente de las tecnologías de la información y la comunicación para realizar compras y calificación de productos, donde los clientes pueden hacer uso de este tipo de medios para dañar la imagen de un producto y/o marca.

2 Desarrollar una oferta orientada al mercado objetivo- Es un modo de focalización de la fidelización, donde es necesario plantar un segmento meta en el cual se pretende hacer uso efectivo de la oferta para que la estrategia surta el efecto deseado. 
3. Diseñar estrategias de marketing desde la perspectiva del cliente- Es imprescindible trazar los límites fronterizos de la fidelización con la orientación específica hacia el cliente, dado que non hacerlo de esta forma, implicaría realizar una inversión necesaria, y por ende el impacto no será muy significativo.

4. Centrarse en aportar soluciones y resultados, no productos- En muchas ocasiones se establece el método cuantificable basándose en el producto a ofrecer y dejando a un lado un enfoque de vital importancia que debe servir como un aporte hacia una solución y cuyos resultados sean medibles, en cuanto esta, soluciona los problemas y llena la carencia de emociones de los clientes, de tal modo que surta un efecto de vinculación a largo plazo.

5. Apoyarse en el cliente para colaborar en la creación de valor- Este paso le brinda un espacio de participación al cliente, donde este se convierte en actor activo del cambio, y coeditor de la oferta comercial.

6. Usar nuevos canales de comunicación para transmitir el mensaje al cliente- En muchos casos los productos o servicios que se ofrecen son excelentes, sin embargo el mensaje enviado al cliente o consumidor no es efectivo; para contrarrestar este efecto, se deben incorporar nuevos canales y medios de comunicación, de tal forma que se cree un entorno comunicativo multidireccional.

7. Desarrollar indicadores claves del proceso y mediciones continuas del ROI- Sin duda alguna, la medición y control de los indicadores de rendimiento, son el mejor mecanismo para demostrar la eficacia de la campaña, tanto a nivel cuantitativo como también, cualitativo.

8. Apostar por un Marketing Científico- Dado el involucramiento de varias ciencias como: estadística, matemática, la psicología y sociología, basándose en las teorías como un pilar de apalancamiento para el logro de los objetivos medibles, previamente planteados.

9. Desarrollar activos de largo recorrido en la compañía- La política de fidelización, debe llegar a convertirse en un proceso continuo y a largo plazo, precisamente porque es de vital sustancia para el mantenimiento de la cuota de clientes,

10. Implantar en la empresa una visión "holística" del marketing- Es necesario rebasar el enfoque de las cuatro letras p: producto, precio, plaza y promoción; enfocándose además en los 
tipos de fidelización de índole experiencial, conductual, emocional, entre otros, Con los cuales se satisfaga la nueva demanda tan exigente del mercado.

Por otra parte, Kolsky, (2014), los clientes pueden experimentar sentimientos positivos acerca de su empresa / marca. Kolsky usa la palabra "amor", para describir este sentimiento de lealtad emocional. Creo que dos modelos de Kolksy de la lealtad del cliente (emocional e intelectual) no son realmente diferentes tipos de lealtad. Simplemente reflejan dos extremos interconectados de un mismo punto continuo. El sentimiento de "amor" de la marca es uno de los extremos de este continuo y la sensación de "indiferencia" está en el otro extremo de este continuo.

Por otra parte, el modelo de la fidelidad de los clientes planteado por Temkin es claramente emocional; que mide la lealtad del cliente mediante preguntas acerca de su disposición a considerar, la confianza y el perdonar, cada uno representando sentimientos positivos cuando alguien "le gusta" una empresa.

Para (Marketing Schools, 2015), muchas compañías se separan las dos funciones y dedican diferentes áreas de su departamento de marketing para trabajar en uno u otro sentido. Los nuevos clientes se consideran transaccional ya que el objetivo es llegar a comprar, mientras que los clientes existentes requieren diferentes estrategias.

En aras de retener a los clientes actuales, las empresas se involucran en las estrategias de marketing relacional para atraer continuamente la repetición de negocios. Si bien ambos tipos de cliente deben ser reconocidos y respetados, el objetivo, en última instancia, es convertir a cada nuevo cliente en un cliente que vuelve.

El marketing de relaciones puede implicar la revisión de los principales aspectos de la forma en que una compañía realiza negocios. Esto puede ser costoso, consume tiempo, y tienen graves consecuencias para los clientes y empleados. La única manera de llevar a cabo una estrategia de marketing relacional de una manera reflexiva y eficaz es seguir un plan de marketing integral.

Las empresas deben primero mirar los datos demográficos e históricos sobre sus clientes para entender lo que son, lo que compran, y la forma de proveer para ellos en el largo plazo. La empresa debe entender por qué un consumidor devuelve la repetición de negocios. Existe la tendencia a pensar que los clientes devuelven porque la empresa les ha servido bien, pero tal vez 
volver a una tienda, ya que es el más cercano a su casa, o el único en la zona que las existencias del producto que desea comprar.

\section{Referencias bibliográficas}

Arquero José Daniel, Rodríguez de Llauder Carlos, Barquero Mario y Huertas Fernando. (2012). Marketing de Clientes ¿Quién se ha llevado a mi cliente? Mexico: McGraw-Hill Interamericana.

Center, M. P. (2012). Instrumentos de análisis del marketing estratégico. Madrid: Díaz de Santos.

Ferrell, M. (2012). Estrategia de marketing. México: Cengage Learning.

García, E. (2011). Marketing y plan de negocio de la microempresa. Barcelona: Paraninfo.

Gronroos, C. (2012). Marketing y gestión de servicios. Madrid: Díaz de Santos.

Kotler, P., \& Armstrong, G. (2011). Fundamentos de marketing. México: Pearson Educación.

Munuera, J. (2012). Estrategias de marketing: un enfoque basado en el proceso de dirección. Barcelona: ESIC.

M. (2014). Atención al cliente. España: Paraninfo, S.A.

Parmelee, D. (2012). Desarrollo exitoso de las estrategias de marketing. Catalunya: Reverte. 